\title{
Bioclimatic modeling of moss distribution: MaxEnt interpretation for test species.
}

\author{
Olga Pisarenko ${ }^{1 *}$, and Natali Makunina ${ }^{1}$ \\ ${ }^{1}$ Central Siberian Botanical Garden SB RAS, 630090, Zolotodolinskaya Str., 101, Novosibirsk, \\ Russia
}

\begin{abstract}
Bioclimatic modeling method MaxEnt is tested to micro-habitats occupying objects on the example of five moss species. Modeling is done out on a planetary and regional scale. Results are discussed.
\end{abstract}

\section{Introduction}

Revealing of species distribution patterns is one of the key problems of contemporary botanical researches; one of possible approaches is the analysis of the relationships of species' habitats and environmental factors. The maximum entropy method MaxEnt is an effective algorithm for modeling of ecological and spatial distribution of species $[1,2]$. This method was created to study the distribution of wild relatives of cultivated plants and over the past decade has been actively used both to study the current distribution of species/communities and to predict potential distribution. By today numerous publications describe ecological niche models and potential habitats of animals and, less often, vascular plants; seldom this method is used to predict plant community areas. Usually MaxEnt models deal with WorldClim climate data [1] obtained by interpolating the average monthly climate data of planet weather stations. When we examine distribution of smallsized objects confined to micro-habitats and neglecting main climate factors (mosses for example), this method applicability is not so obvious: publications about bioclimatic modeling of moss species areas are rare $[4,5,6]$. Total areas of most mosses are very wide: often it covers several continents and several bioclimatic zones, but ecological demands of species in different parts of areas can be different. To approve this idea we tested the applicability of MaxEnt to mosses on example of Crossidium squamiferum (Viv.) Jur. [7], it was an example of species with narrow ecological and wide spatial distribution. Our next step was the comparison of MaxEnt algorithm results of models in planetary and regional scale.

\section{Materials and methods}

Aulacomnium turgidum (Wahlenb.) Schwägr., Eurhynchium angustirete (Broth.) T.J.Kop., Jaffueliobryum latifolium (Lindb. \& Arnell) Ther., Rhytidium rugosum (Hedw.) Kindb.,

* Corresponding author: o_pisarenko@,mail.ru 
Stegonia latifolia (Schwägr.) Venturi ex Broth were chosen as test objects. These species live on soil and on rock outcrops. Stegonia latifolia and Jaffueliobryum latifolium are small mosses (less than 2-5 mm tall); other mosses are quite large, with stems up to $10 \mathrm{~cm}$, they can be sodominants and dominants. Eurhynchium angustirete is a Eurasian species with a disjunctive area; other mosses are disjunctively distributed in the Holarctic. E. angustirete tends to coniferous and broad-leaved forests, it is classified as a hemiboreal species. J. latifolium is an arid species, most common in Mongolia, South Siberia and North America. A. turgidum and S. latifolia have Arctic-Alpine areas. R. rugosum is common in the Arctic, in the mountains it grows from the steppe belts up to highlands, on stony substrates it can be found on the plain.

Geo-linked location data were taken from GBIF.org [8], from the database "Herbarium specimens of mosses of Russia" [9], and from the database of geobotanical releves and floral finds of authors within the Altai-Sayan mountain region. Two tables of localities were formed for each species: 1) general, including non-duplicated coordinates of from all planet, and 2) regional, including locality coordinates within the Altai-Sayan mountain region. In the Altai-Sayan region Rhytidium rugosum is the most frequent and widespread species among the listed; the range of its habitats is the widest. Therefore Rhytidium rugosum regional set of localities was divided into sub-sets according to main types of its habitats: stony steppes, mountain tundras, forests, and rock outcrops.

For sets of each species, 19 bioclimatic variables with a resolution of 5 arc-minutes per pixel were analyzed, they were averaged over the period 1950-2000. These variables are: bio1 - annual average temperature; bio2 - amplitude of daily average temperature; bio3 (bio1/bio7) * 100; bio4 - the standard deviation of temperatures; bio5 - maximal temperature of the warmest month; bio6 - minimal temperature of the coldest month; bio7 annual temperature amplitude (bio5 - bio6); bio8 - average temperature of the wettest year quarter; bio 9 - average temperature of the driest year quarter; bio10 - average temperature of the warmest year quarter; bio 11 - average temperature of the coldest year quarter, bio12annual precipitation amount; bio13 - precipitation amount of the wettest month; bio14 precipitation amount of the driest month; bio15 - precipitation variation coefficient; bio16 - precipitation amount in the wettest year quarte; bio17 - precipitation amount in the driest year quarter; bio18 - precipitation amount in the warmest year quarter; bio19 precipitation amount in the coldest year quarter [1].

A series of raster layers $(90 \mathrm{~m} /$ pixel resolution) was created for the Altai-Sayan mountain region (hereinafter ASMR): *bioclimatic variable BIOCLIM (19 rasters), *monthly average temperatures (12 rasters), *monthly precipitation (12 rasters), *monthly solar radiation (12 rasters), *hypsometric indicators (3 rasters: height, exposition, inclination), *NDVI index (3 rasters: may, July, September).

Preliminary analysis of regional models has shown the key influence of 3-6 variables (the total variable number is 61): their contribution in model surpasses 5\%. As result 19 bioclimatic variables and 3 hypsometric ones were chosen, variables with negligible contribution were excluded from further analysis. MaxEnt models were created for regional samples and subsamples of all species. Random test percentage is 25\%; maximum iterations $=1500$. Visualization of potential species areas was realized using QGis18.5.3.

\section{Results and discussion}

All the models have AUC index $>0.8$, so all them are reliable. The results are partly shown in tables 1-2. According to MaxEnt models, the potential moss areas are influenced by the following factors.

Eurhynchium angustirete. Variables bio1, bio2 and bio14 make the greatest contribution to the planetary distribution model (table 1); this fact, taking into account the response 
curves, can be interpreted as species tendency to localities with average annual temperatures $0-10{ }^{\circ} \mathrm{C}$, small amplitude of average daily temperatures, and constant humidity without dry period. Regional model has shown the importance of variables bio6, bio1, and bio7 (tab.1): minimum temperature of the coldest month of the year is critical; according to the response curve, the probability of species finding falls sharply with its decrease; the optimum of the species lies in a narrow range of the average annual temperature and the annual temperature amplitude. In the ASMR the potential areas of this species covers low mountains of the humid sector (Fig. 1, a) and centered in the North Altai and the Mountain Shoria.

Table 1. Contribution of bioclimatic variables to the models of test mosses on the Earth

\begin{tabular}{|c|c|c|c|c|c|c|c|c|c|c|}
\hline & \multicolumn{2}{|c|}{ E.angustirete } & \multicolumn{2}{|c|}{ A. turgidum } & \multicolumn{2}{|c|}{ S. latifolia } & \multicolumn{2}{|c|}{ J.latifolium } & \multicolumn{2}{|c|}{ R. rugosum } \\
\hline $\begin{array}{l}\mathrm{N} \text { records } \\
\text { train / test }\end{array}$ & \multicolumn{2}{|c|}{$1066 / 355$} & \multicolumn{2}{|c|}{$1077 / 358$} & \multicolumn{2}{|c|}{$252 / 84$} & \multicolumn{2}{|c|}{$162 / 53$} & \multicolumn{2}{|c|}{$1641 / 547$} \\
\hline $\begin{array}{l}\text { AUC } \\
\text { train/test }\end{array}$ & \multicolumn{2}{|c|}{$0.947 / 0.944$} & \multicolumn{2}{|c|}{$0.896 / 0.896$} & \multicolumn{2}{|c|}{$0.949 / 0.931$} & \multicolumn{2}{|c|}{$0.974 / 0.951$} & \multicolumn{2}{|c|}{$0.881 / 0.875$} \\
\hline & PC & PI & PC & PI & PC & PI & PC & PI & PC & PI \\
\hline bio1 & 42.5 & 41 & 5.6 & 8.3 & 0.2 & 0.4 & 9.4 & 6.6 & 21.7 & 5.1 \\
\hline bio2 & 20.5 & 9.6 & 0.7 & 3.3 & 0.9 & 2.5 & $\underline{24.6}$ & 1.4 & 0.2 & 0.8 \\
\hline bio3 & 8.7 & 13.6 & 15.4 & 19.3 & 9 & 5 & 4 & 19.7 & 2.9 & 3.3 \\
\hline bio5 & 7.6 & 4.6 & 7.9 & 3.2 & $\underline{46.7}$ & 1.2 & 0.8 & 0.7 & 22.4 & 2 \\
\hline bio7 & 1 & 0 & 2.2 & 1 & 4.8 & $6 / 6$ & 10.9 & 4.8 & 7.3 & 4.7 \\
\hline bio8 & 0.6 & 0 & 2 & 6.3 & 7 & 3.4 & 11.4 & 3.7 & 1.3 & 9.7 \\
\hline bio10 & 0.8 & 2.5 & $\underline{60.2}$ & 26.2 & 13.3 & 22.3 & 0.1 & 0.5 & 14.6 & 15.4 \\
\hline bio14 & 15.1 & 16 & 0 & 0.2 & 0 & 0.3 & 0 & 0.2 & 20.1 & 9.8 \\
\hline
\end{tabular}

*Variables with contribution $>10 \%$ in at least one samle were included. High values are boldered; the maximum values are underlined. PC - variable contribution, \%; PI - permutation importance.

Table 2. Contribution of bioclimatic variables to the distribution models of mosses in the Altai-Sayan mountain region

\begin{tabular}{|c|c|c|c|c|c|c|c|c|c|c|}
\hline & \multicolumn{2}{|c|}{ E.angustirete } & \multicolumn{2}{|c|}{ A. turgidum } & \multicolumn{2}{|c|}{ S. latifolia } & \multicolumn{2}{|c|}{ J.latifolium } & \multicolumn{2}{|c|}{ R. rugosum } \\
\hline $\mathrm{N}$ records & \multicolumn{2}{|c|}{26} & \multicolumn{2}{|c|}{56} & \multicolumn{2}{|c|}{30} & \multicolumn{2}{|c|}{35} & \multicolumn{2}{|c|}{87} \\
\hline$A U C$ & 0.98 & .942 & 0.96 & .944 & 0.99 & .954 & 0.93 & .900 & 0.92 & 0.885 \\
\hline & PC & PI & $\mathbf{P C}$ & PI & PC & PI & PC & PI & PC & PI \\
\hline bio1 & 20.9 & 10.6 & 1.9 & 6.3 & 0 & 0 & 1.5 & 0.6 & 14.1 & 12.5 \\
\hline bio5 & 5.7 & 2.4 & 9.9 & 31 & 11.1 & 0 & 2.1 & 0 & 0.1 & 0.2 \\
\hline bio6 & 23.6 & 27.3 & 12.2 & 0.8 & 7.6 & 0.5 & 2.3 & 0.3 & 13.2 & 4.5 \\
\hline bio7 & 19.4 & 43.6 & 20.1 & 3.1 & 0 & 0 & 12.7 & 3.3 & 32.9 & 15.7 \\
\hline bio10 & 0 & 0 & 25.5 & 23 & 32.9 & 35 & 3.4 & 7.4 & 0 & 0.2 \\
\hline bio13 & 0 & 0 & 2.8 & 6.5 & $\overline{13.7}$ & 20.7 & 10 & 18.9 & 0.4 & 6 \\
\hline bio15 & 15.6 & 10.7 & 4.5 & 6 & 8.6 & 0.5 & 11.5 & 15.5 & 5.1 & 22.5 \\
\hline bio16 & 0 & 0 & 0.2 & 0 & 1.7 & 0 & 16.7 & 6.7 & 3.4 & 0.6 \\
\hline steepnes & 7.8 & 2.5 & 6.9 & 7.7 & 0.7 & 0.4 & 16.6 & 16.1 & 4.3 & 2.1 \\
\hline
\end{tabular}

Stegonia latifolia. In the planetary model, variable bio5 (T max of the warmest month of the year) is crucial (table 1): the probability of species finding $>50 \%$ is limited to the temperature range of $2-18{ }^{\circ} \mathrm{C}$. In the regional model, variable bio10 has the maximum contribution (table 2): according to the response curve, the probability of species finding $>$ $50 \%$ is limited by temperature range $7-11^{\circ} \mathrm{C}$. Variable bio13 (the amount of precipitation in the wettest month of the year) is also important: when it exceeds $60 \mathrm{~mm}$, the probability of species finding drops sharply. The potential area of this species in ASMR encompasses the semiarid sector (Fig. 1, b) - the highlands of the South-East Altai and the South Tuva. 
Aulacomnium turgidum. In both the planetary and regional models, variable bio10 has the highest contribution (tab. 1, 2): according to the response curve when the average temperature of the warmest year quarter rises above $+10^{\circ}$, the probability of species finding drops sharply. In regional model variable bio7 and bio6 are also significant; optimal for this species in ASMR is the annual temperature amplitude $10-20^{\circ}$. In the ASMR the potential area of this species covers the highlands of the semihumid and humid sectors (Fig. 1, c).

Jaffueliobryum latifolium. In the planetary model, variable bio2 has the largest contribution (table 1); the probability of species finding correlate with its growth. In the regional model, variable bio16 (amount of precipitation in the wet quarter of the year) has the largest contribution (table 2); when it overpasses $200 \mathrm{~mm}$, the probability of species finding drops sharply. The potential area of this species in South Siberia is very wide (Fig. $1, d)$, it covers semihumid and semiarid sectors, except highlands and mountain basins. In reality, the findings of this species occur on rock outcrops on steep slopes in mountains and steep riversides on the plain. In the regional model, this fact is confirmed by high contribution of variable "steep_asms", included slope steepness values (table 2).
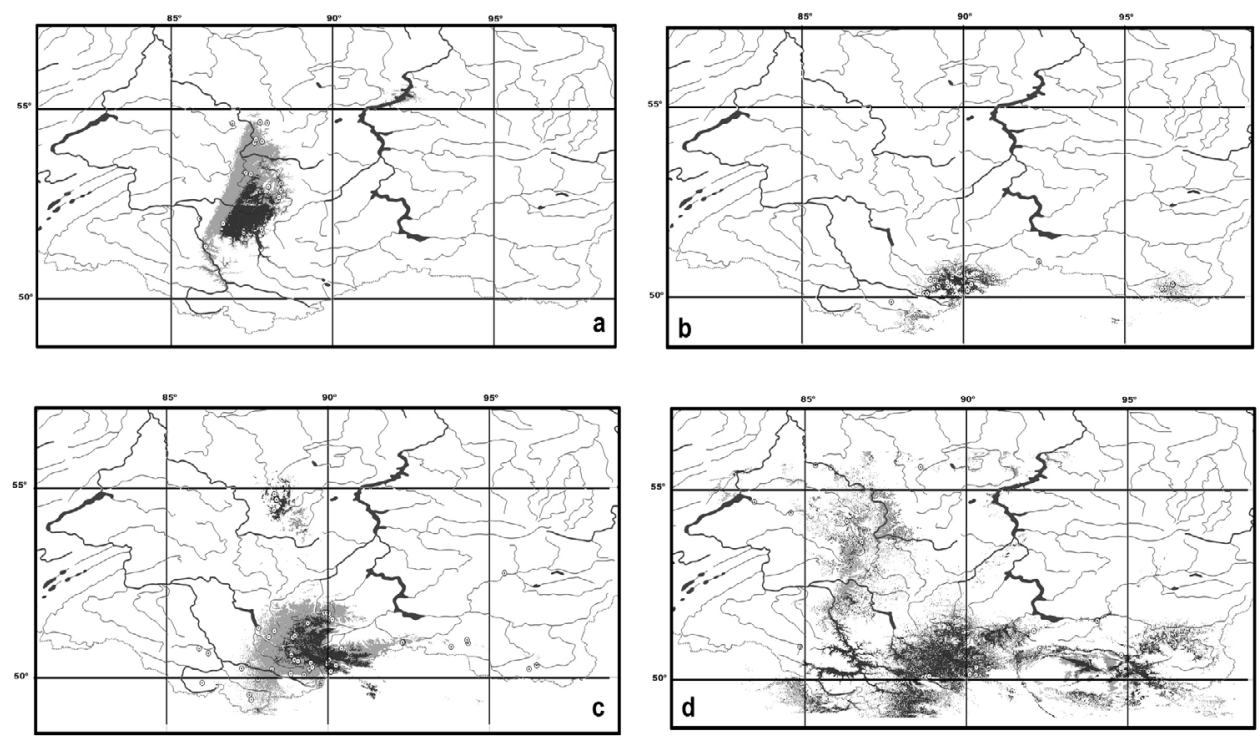

Fig. 1. Potential areas of moss species in the Altai-Sayan mountain region. a - Eurhynchium angustirete; $\mathrm{b}$ - Stegonia latifolia; $\mathrm{c}$ - Aulacomnium turgidum; $\mathrm{d}$ - Jaffueliobryum latifolium. *here and in Fig.2 light gray fill - probability of species finding is $0.5-0.7$, dark grey fill - probability is more than 0.7

Rhytidium rugosum. In the planetary model, variable bio5, bio1 and bio14 make the same high contribution: according to the recall curve optional maximal temperature of the warmest month lies within $10-22^{\circ} \mathrm{C}$, optimal average annual temperature covers range from -2 to $+11^{\circ} \mathrm{C}$, optimal amount of precipitation in the driest month changes from 20 to 80 $\mathrm{mm}$. In the regional model, variable bio7 has the highest contribution (tab. 1, 2).

Rhytidium rugosum has the largest area among all test species; it covers the entire Altai, Salair, Kuznetsk basin and foothill plains (Fig. 2a). In fact $R$. rugosum does not occur everywhere: subsample models are shown to be more adequate. This species is widespread in the ASMR highlands (Fig. 2b): according to the response curves, the probability of species finding gradually decreases with the average temperature of the warmest year quarter increase and with the annual precipitation amount increase. In the Northern lowland part of ASMR this species occurs only in petrophytic steppes (Fig. 2c), but here steppes are 
quite rare: they occur only on steep sunny slopes of hills and river valleys. In the ground cover of forest communities $R$. rugosum is found exclusively in the southern part of the region: its abundance delimits the forests of the semiarid sector (Fig. 2d).
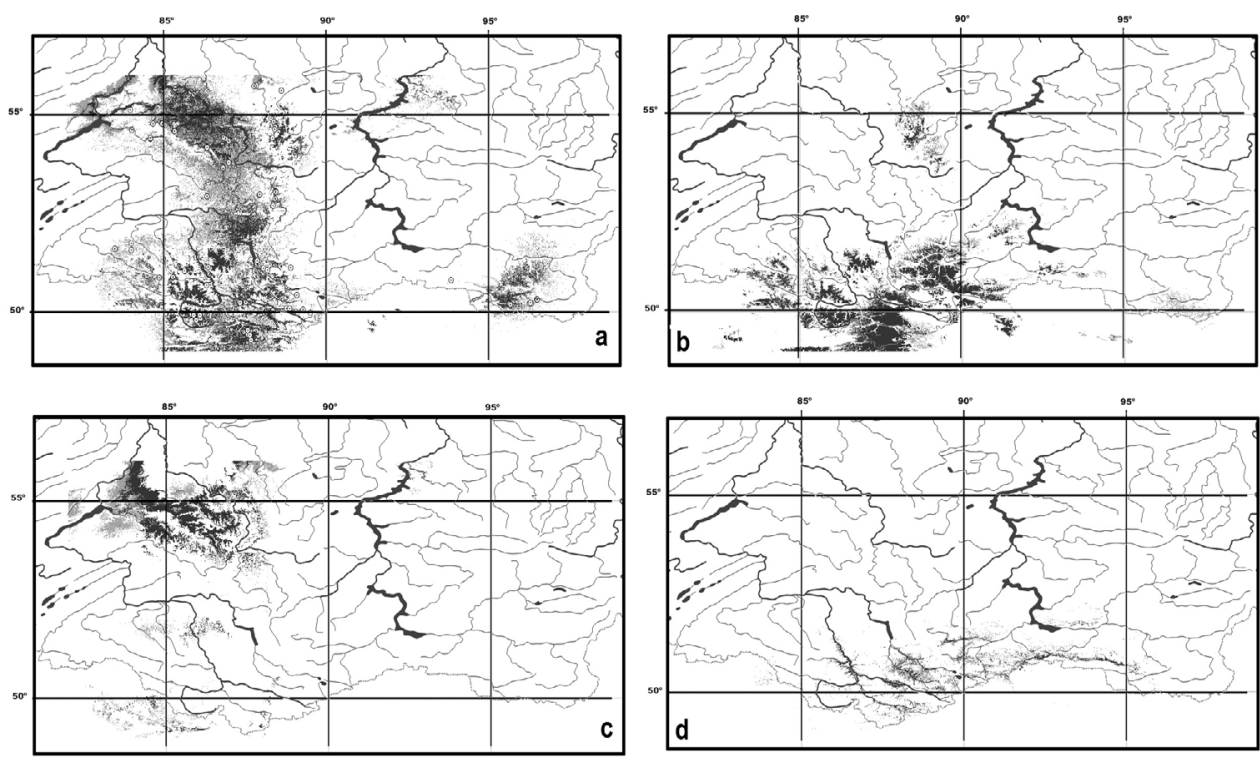

Fig. 2. Potential area of Rhytidium rugosum in the Altai-Sayan mountain region. a - based on total list of localities; b - in mountain tundra; c - in petrophytic steppes; $d$-in the ground cover of forests.

Thus, the application of bioclimatic modeling method to objects associated with microhabitats allows us to create reliable models at both planetary and regional level. Modeling at the regional level is more correct: it allows us to take into account the nuances of the species ecology, areas based on specialized sample (subsample) models are more realistic.

The work was supported by grant no. 18-04-00822; author's samples are in biocollection USU 440537

\section{References}

1. S.J. Phillips, M. Dudik, Ecography. 31, 161-175 (2008).

2. S.J. Phillips, A Brief Tutorial on Maxent (American Museum of Natural History, New York, 2017)

3. Global climate and weather data. http://www.worldclim.org

4. A.E. Désamoré, B. Laenen, M. Ctech, B. Papp, L. Hedenäs, R.G Mateo, A. Vanderpoorten, Global Change Biology 18, 2915-2924 (2012).

5. G. Mateo, A. Vanderpoorten, J. Muňoz, B. Laenen, A.E. Désamoré. PLoS ONE 8, e55648 (2013)

6. S. Song, X. Liu, X. Bai, Y. Jiang, X. Zhang, C. Yu, PLoS ONE 10, e0132346. (2015)

7. D.V. Sandanov, O.Yu. Pisarenko, Arctoa 27, 29-34. (2018).

8. GBIF https://www.gbif.org

9. Herbarium specimens of Russian mosses http://arctoa.ru/Flora/basa.php 